\title{
Study of the Gravity Model Based on International Cases
}

\author{
Siyuan Zhang \\ North China Electric Power University(Baoding), Baoding 071000, China \\ 593736114@qq.com
}

Keywords: gravity model, LPI, Maritime Silk Road, numerical computation, trade

\begin{abstract}
Referring to relevant data, the Maritime Silk Road is concerned with several countries Asian and African countries. Cooperation and development are the core of this strategy. Combining the history of the Maritime Silk Road, we mainly focus on the international trade, where high trade efficiency is required. Logistics Performance Index (LPI), which can assess the efficiency of the trade, is an effective indicator to evaluate the development of the Maritime Silk Road. In addition, relationships between China and other countries do influence the trade quantity. We first analyze the historical background of proposing the Maritime Silk Road in 21st century with data integrated. Then, we try to focus on the economic circle and study the international trade to analyze LPI and economic relationships between China and other countries. What's more, we set up an extended model, based on the original Gravity Model, to study the short-term impact of the development strategy of the Maritime Silk Road on China.
\end{abstract}

\section{Introduction}

A strategic concept of constructing the Maritime Silk Road in 21st century was proposed by the Chinese President Xi Jinping in October 2013, which intends to be an advocation of cooperation and development, and a combination of politics, economics and culture. Policy communication, roads linked together, trade unblocked, currency circulation and public connected are considered to be the five main parts of the Maritime Silk Road, among which, an unimpeded trade is the key point as well as the foundation of the Maritime Silk Road, and act as a bridging character linking the rest aspects [Tan Xiujie and Zhou Maorong 2015]. Based on the fact, we mainly aim at the trade area and analyze in terms of the total volume of trade.

\section{Historical Background}

The Maritime Silk Road could be traced back to the Han Dynasty originally, while enjoyed a prosperity in the Tang, Song and Yuan Dynasties. Formed by a succession of port branches in the western and oriental oceans at that time and presented as a network of the global trade, it had been an effective bond connecting China with other countries. For the duration, development was obvious in all areas including the circles of politics, economics and culture. The pattern of the western world changed rapidly in the Tang, Song, Yuan dynasties, plus the breakthrough of navigation and the unprecedented demand of economics and trade, leading to the peak of the Maritime Silk Road. Chinese silk, porcelain, spices, tea and other items were exported to the Arabia as well as other Asian and African countries from coastal ports in the southeast, through South China Sea, Persian Gulf, Red Sea, etc as shown in Figure 1. Meanwhile, property including spices, wool and ivory were imported to China from overseas. 


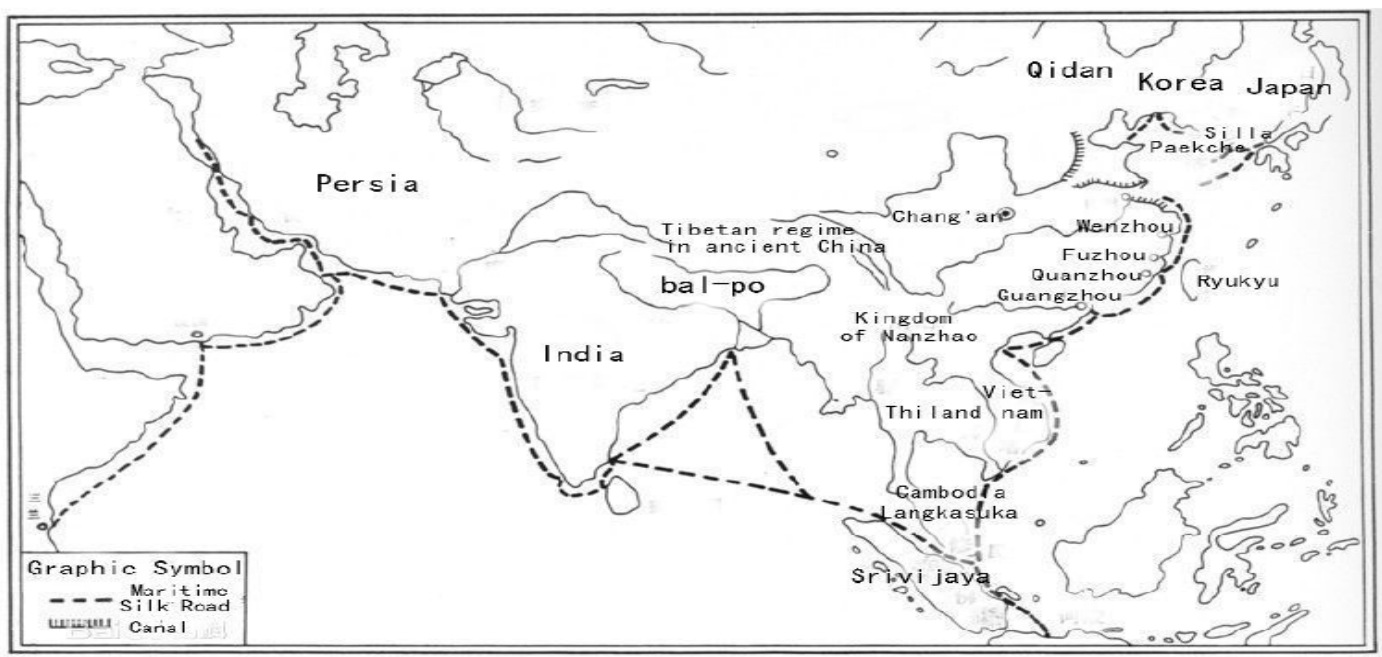

Figure 1. A sketch map of the Maritime Silk Road in Tang Dynasty(Source: entry photo of Baidu encyclopedia)

Extensive and abundant human activities were available, including the expansion of the ship route, conversation and progress of the marine technology, flows of the foreign nationals, exchanges of the official envoy, spread of the religion, music and art, proliferation of exotic species, and so on. In Yuan Dynasty, Marco Polo arrived in China by the Silk Road and returned from the port of Quanzhou located at the Maritime Silk Road toItally. His journals deeply influenced the expectation of the Europe to the orient in the Medieval. A direct acceleration was produced to the Western Europe Uncharted Waters and the great geographical discoveries according to the Maritime Silk Road. [ Baidu encyclopedia] Nevertheless, the application of the Maritime Silk Road had been shelved since the Ming Dynasty, when the policy of forbidding sea voyages was established. The rise and decline of the Maritime Silk Road witnessed the outstanding achievement of the ancient navigation career, connected with the experience as well as lessons obtained from vicissitudes of the country. Only after the re-exposure of the topic by Chinese President Xi Jinping in21st century did a second life was injected into the strategy. Since then, strategic initiative is valued to increase investments and foster collaboration across the historic Silk Road, while corporation has been tightened among the countries along the Maritime Silk Route, followed by a series of gratifying scenes. Figure 2 shows China's total imports and exports during the recent period [UN Comtrade data].Among these pictures, the red line with “*” points indicates export to the other country, while the blue line with “。” points indicates import from the other country.

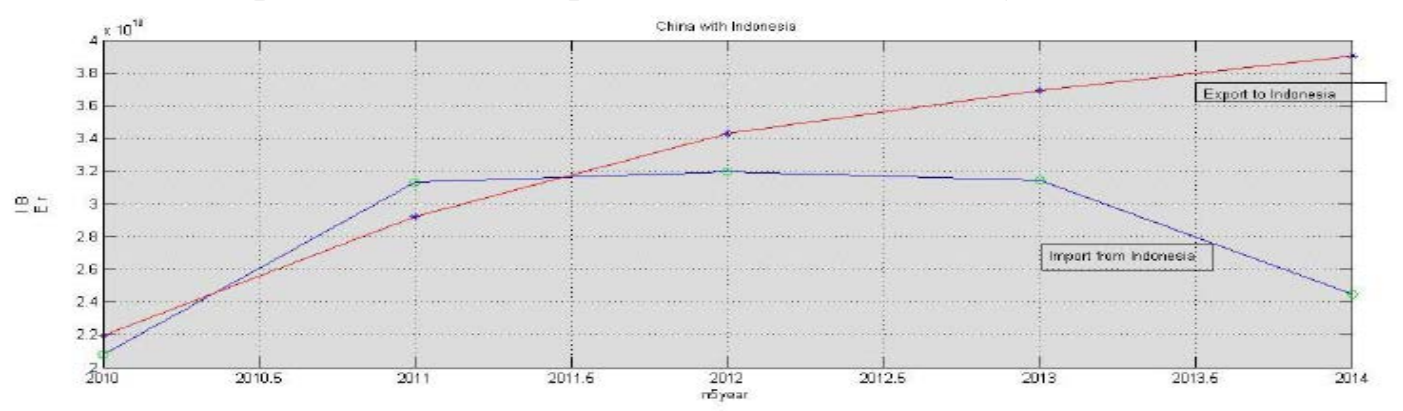

(a)

Figure 2

Since economic indicators like GDP and LPI are reflections of the historical background of proposing the Maritime Silk Road, we obtain the data from World Bank database, which is collected and presented in Table1.We will analyze the statistics later in the economic indicators part. 


\begin{tabular}{|c|c|c|c|c|c|}
\hline & 2010 & 2011 & 2012 & 2013 & 2014 \\
\hline Iran & $422,568,112,862$ & $576,556,625,6355$ & $557,935,497,766$ & $493,798,398,466$ & $415,338,504,536$ \\
\hline Egypt & $218,888,324,505$ & $236,001,858,960$ & $262,824,255,568$ & $271,972,822,883$ & $286,538,047,766$ \\
\hline Japan & $5,495,385,617,892$ & $5,905,632,338,015$ & $5,954,476,603,962$ & $4,919,563,108,373$ & $4,601,461,206,885$ \\
\hline Korea & $1,094,499,350,177$ & $429,072,838,477$ & $407,575,109,733$ & $428,321,937,480$ & $436,343,622,435$ \\
\hline Sri Lanka & $49,565,557,439$ & $59,180,578,839$ & $59,391,495,533$ & $67,206,129,445$ & $74,941,183,242$ \\
\hline China & $6,039,658,508,486$ & $7,492,432,097,810$ & $8,461,623,162,714$ & $9,490,602,600,148$ & $10,360,105,247,908$ \\
\hline Malaysia & $247,533,525,881$ & $289,326,512,787$ & $304,956,531,562$ & $313,158,247,643$ & $326,933,043,801$ \\
\hline Singapore & $236,420,337,821$ & $275,369,805,947$ & $289,941,106,344$ & $302,245,904,260$ & $307,871,907,186$ \\
\hline India & $1,708,458,876,830$ & $1,835,814,449,585$ & $1,831,781,515,472$ & $1,861,801,615,478$ & $2,066,902,397,333$ \\
\hline Pakistan & $177,406,854,515$ & $213,755,282,059$ & $224,646,134,571$ & $232,286,781,111$ & $246,876,324,189$ \\
\hline \multicolumn{5}{|c|}{ Source: } & http://data.worldbank.org/ World Bank database \\
\hline
\end{tabular}

(a)

\begin{tabular}{|c|c|c|c|c|c|}
\hline & 2010 & 2011 & 2012 & 2013 & 2014 \\
\hline Iran & 2.570 & 2.530 & 2.490 & 2.480 & 2.460 \\
\hline Egypt & 2.600 & 2.800 & 3.000 & 3.000 & 3.000 \\
\hline Japan & 3.970 & 3.950 & 3.930 & 3.920 & 3.910 \\
\hline Korea & 3.600 & 3.650 & 3.700 & 3.700 & 3.700 \\
\hline Sri Lanka & 2.290 & 2.520 & 2.750 & 2.725 & 2.700 \\
\hline China & 3.490 & 3.370 & 3.250 & 3.390 & 3.530 \\
\hline Malaysia & 3.440 & 3.465 & 3.490 & 3.540 & 3.590 \\
\hline Singapore & 4.090 & 4.110 & 4.130 & 4.065 & 4.000 \\
\hline India & 3.120 & 3.100 & 3.080 & 3.084 & 3.088 \\
\hline Pakistan & 2.530 & 2.680 & 2.830 & 2.830 & 2.830 \\
\hline \multicolumn{7}{|l|}{ Source: } & http://data.worldbank.org/ World Bank database \\
\hline
\end{tabular}

(b)

Table 1. Data of some economic indicators

(a) GDP of ten countries (units: current dollars)

(b) LPI (Logistics Performance Index) often countries From the historical evolution of the Maritime Silk Road, we can see the profound and powerful impact of the oceans and maritime trades on countries. Therefore, the strategic concepts of constructing the Silk-Road Economic Belt and the Maritime Silk Road are supposed to be attached great importance to and well implemented, which has a positive and far-reaching influence on the Maritime Silk Road in21st century. 
Terminology and Definitions

\begin{tabular}{lcc}
\hline Variables & Property & Units \\
\hline Trade $_{\boldsymbol{i j}}$ & $\begin{array}{c}\text { Import and export trade } \\
\text { between china and partners }\end{array}$ & One hundred million\$ \\
$\boldsymbol{G D P}_{\boldsymbol{i}}$ & China's gross domestic product & One hundred million\$ \\
$\boldsymbol{G D P}_{\boldsymbol{j}}$ & J's gross domestic product & One hundred million\$ \\
Distwces $_{\boldsymbol{i c}}$ & $\begin{array}{c}\text { Distance between China and } \\
\text { trading partners }\end{array}$ & Kilometer \\
$\boldsymbol{A S E A N}_{\boldsymbol{j}}$ & Whether members of the SCO & \\
$\boldsymbol{L P I}_{\boldsymbol{i j}}$ & (Only China, India and Pakistan) & \\
$\boldsymbol{U}_{\boldsymbol{i j}}$ & International Logistics Performance Index \\
\hline
\end{tabular}

\section{Model}

\section{Model Overview}

The trade gravity model can be used to study the relationship between trade scale and GDP of various countries as well as distance from one country to another. Trade scale between two countries is proportional to GDP of the two while in inverse proportion to their distance. The basic function of the trade gravity model is presented as

$$
\text { LnTrade }_{i j}=C_{0}+C_{1} \text { LnGDP }_{i}+C_{2} \text { LnGDP }_{j}+C_{3} \text { Distwces }_{i c}+u_{i j}
$$

Based on the trade gravity model, the expanded equation we make is shown as

$$
\text { LnTrade }_{i j}=C_{0}+C_{1} \operatorname{LnGDP}_{i}+C_{2} \text { LnGDP }_{j}+C_{3} \text { Distwces }_{i c}+C_{4} A S E A N_{i j}+C_{5} \text { LnLPI }_{i j}+C_{6} \text { Lnu }_{i j} \text { (The }
$$
expectations reveal that $\mathrm{C} 5>0$ and $\mathrm{C} 6>0$ )

\section{References}

[1]The Reform of EU Emissions Trading Scheme Phase III 《Wuhan University Journal》, 2013

[2]The Impact of Transport on International Trade Development, Acta Economica Et Turistica 13-28, 2016

[3]Estimating Potential Trade Links in the International Crude Oil Trade: A Link Prediction Approach, 10.1016/j.energy.2016.02.099,2016

[4]Evolution of international trade and investment networks 10.1016/j.physa.2016.06.117, 2016

[5]UN Comtrade data http://viz.ged-project.de/

[6]World Bank database http://data.worldbank.org/ 